\title{
A Comparative Analysis of the Graduation Resources Used by the Defense Lawyers in Chinese and American Courts_-A Case Study of the Wang Chengzhong Case and the Stump Case ${ }^{1}$
}

\author{
Songman Liang Shaomin Zhang* \\ School of English for International Business, Guangdong University of Foreign Studies, 2 North Baiyun \\ Avenue, Guangzhou 510000, China \\ * E-mail of the corresponding author: zhangliang20201213@163.com
}

\begin{abstract}
Based on one of the subsystems of the appraisal system - the graduation system, this article analyzes the utterances of the defense lawyers in the Stump case and the Wang Chengzhong case to compare the similarities and differences of the graduation resources by the defense lawyers on both cases, to reveal the reasons behind them, and to explore what role these graduation resources play in court defense discourse. The study found that the overall trends of the graduation resources used by the defense lawyers in the Stump case and the Wang Chengzhong case are similar. Both parties prefer to use force resources while use focus resources less frequently. This is mainly related to the effects of different kinds of graduation resources and the responsibilities of defense lawyers. In focus resources, in Wang Chengzhong case, the proportion of sharpening resources is significantly higher than that of softening resources, while in Stump case, the proportion of softening resources is higher than that of sharpening resources. This may be related to the differences of eastern and western thinking pattern and the nature of these two different cases.
\end{abstract}

Keywords: graduation system, defense lawyers, courtroom discourse, case study

DOI: $10.7176 /$ JLLL/74-01

Publication date: December $31^{\text {st }} 2020$

\section{Introduction}

Since put forward, the appraisal system has received wide attention at home and abroad. In China, those scholars' study on the appraisal system develops from the initial introduction and evaluation stage (Wang, 2001; Wang \& $\mathrm{Ma}, 2007)$ to application stage, that is, applying the appraisal system to various discourses, such as court discourses (Yuan \& Hu, 2010; Zheng, 2013). However, the previous studies mainly study courtroom discourse from the perspective of attitude system and engagement system (Han \& Mao, 2010; Jiang, 2016), rarely involve the graduation system. Although the graduation system is also widely used to analyze various discourses (Dong, 2012; Munday, 2015; Xie, 2017), the application of the graduation system in court discourse is still a research gap. The graduation system runs through the appraisal system, and Martin and White (2005) have pointed out that the graduation system plays a central role in the entire appraisal system. During court debates, the defense lawyer's arguments can help prove the defendant's innocence, misdemeanor or prove that legal liability should be reduced or even exonerated from him. Proper use of graduation resources can enhance the persuasiveness of defense lawyers' discourse, so it is important to explore the defense discourses of defense lawyers from the graduation system to safeguard the legitimate rights and interests of the accused, to prevent the occurrence of wrongful cases, and ultimately to promote the realization of judicial fairness and social justice. Both the Wang Chengzhong case and the Stump case have received great attention concerning the system of immunity of judges from liability, especially the case of Wang Chengzhong, which has significant implications on China's efforts to establish and improve the system of immunity from of judges from liability. Therefore, this paper based on the graduation system, taking the Wang Chengzhong and Stump cases as examples, compares and analyzes the use of various graduation resources by the defense councils in court debates, and aims to reveal how the defense lawyers use the graduation system to persuade judges so as to defend the legitimate rights and interests of defendants and to help them reduce legal liability or even be exempted.

\section{Theoretical Foundation and Literature Review}

\subsection{Applied research on appraisal system}

The appraisal system proposed by Martin et al. in the 1990s is regarded as a development of interpersonal meaning in Systemic Functional Linguistics (Martin, 2000; Wang, 2001). The appraisal system consists of three subsystems: attitude, engagement and graduation. The graduation system runs throughout the whole appraisal system, and Martin and White have pointed out that graduation is central to the entire appraisal system (Martin and White, 2005). Graduation describes the degree of attitude and engagement, so its greatest characteristic is gradability. The

\footnotetext{
${ }^{1}$ This work is supported by the National Social Science Project of China (Project No.: 20BYY073)
} 
graduation system is divided into force and focus. Force covers assessments as to degree of intensity and as to amount (Martin and White, 2005). Force includes intensification and quantification. The evaluation of degree of Intensification operates over qualities and processes while the evaluation of degree of quantification operates over number, mass and extent. Focus applies most typically to categories which, when viewed from an experiential perspective, are not scalable (Martin and White, 2005). Focus includes "sharpen" and "soften". Sharpening is similar to " emphasizer" and softening is similar to "hedge" (Wang, 2001). The composition of the graduation system is shown in Figure 1.

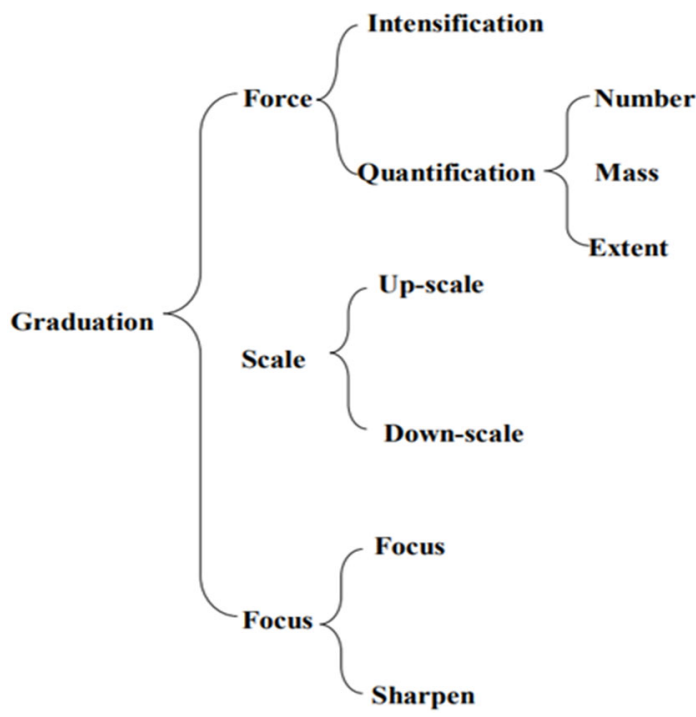

Figure 1. The Graduation System (Martin \& White, 2005)

\subsection{Applied research on appraisal system}

As the appraisal system is very important to explore the interpersonal meaning of discourses, the appraisal system has gained wide attention from scholars at home and abroad since put forward. As one of the three subsystems of the appraisal system, the graduation system is also widely used in various discourses, such as academic discourses (Xie, 2017; Wang \& Guan, 2016), debate discourses (Dong, 2012), literary texts (Fu \& Fu, 2009), news discourses (Jiang \& Xu, 2019), translation discourses (Munday, 2015; Shi \& Gao, 2019), concession addresses (Li \& Li, 2019). For example, Wang \& Guan (2016) made a comparative analysis of graduation resources used in English and Chinese linguistics book reviews, and found that there are a large number of graduation resources in English and Chinese linguistics book reviews, but English and Chinese linguistics book reviews show their own characteristics in terms of force and focus. Munday (2015) explored what position translators take through graduation resources, and found that the application of up-scaling resources can reflect the translator's degree of 'investment' in a proposition and control over the text receiver's response. Yue (2012) explored how writers use graduation resources to naturalize value positions and construe readers and found there are three means of naturalization: foregrounding and backgrounding by up-scaling and down-scaling; invoking judgment and appreciation through differing modes of expressions and lines of meanings; and conveying attitude by strategically distributing graduation resources throughout the discourse.

In the court discourse, the appraisal system as well as the attitude and engagement subsystems has been widely used (Pan, 2008; Han \& Mao, 2010; Yuan \& Hu, 2011; Jiang, 2016). For example, Yuan \& Hu (2011) integrated appraisal system with adaptation theory and constructed an analytical model of adaptation analysis of engagement resources to analyze the regularities of using engagement resources in lawyer representation and to explicate how they are used to adapt to contexts, thus actualizing their communicative aims. Pan (2008) made a comparative analysis of engagement resources to explore how prosecutors and defense lawyers use external voices to strengthen their views and to introduce the strategies for persuading judge during courtroom debates. Chen \& Sun (2020) took the appraisal theory and the focus information function theory as the theoretical framework to explore the type, quantity, intonation, affect and attitude of the rhetorical questions used by prosecutors in courtroom discourse.

To sum up, previous studies mainly focus on the attitude system and engagement system to study the court discourse. Although the graduation system is also widely used in all kinds of discourse, the study of the graduation system in courtroom discourse remains a research gap. The graduation system runs through the whole evaluation system, and the graduation system occupies a central position in the whole evaluation system (Martin and White, 2005). Graduation resources play an important role in persuading judges and others, so this paper adopts the 
graduation system as a theoretical framework to compare the graduation resources used by the defense councils in court debates in the Wang Chengzhong case and Stump case. The three specific questions are as follows.

\section{Research Design}

The corpus is collected from the Wang Chengzhong case and the Stump v. Sparkman case. Both Wang Chengzhong and Stump are judges, of whom Wang Chengzhong appealed against a first-instance verdict in an accusation of perverting the law in a civil case, while Stump was indicted for approving a mother's petition for sterilization of her mildly mentally disabled daughter. Both these two cases involve immunity of judges from liability. As the purpose of this paper is to compare and analyze the use of graduation resources used by the defense lawyers in these two cases, the court trail discourses of the defense lawyers are selected. The total number of words is 10184, of which the number of words in the Wang Chengzhong case is 6068 and the number of words in the Stump case is 4116 . With the help of UAM Corpus Tool 3.3 developed by O'Donnell, this article chooses a combination of quantitative and qualitative research methods. First all the collected corpus is annotated manually and then the frequencies of various types of graduation resources are counted, and finally typical examples in these two cases are selected for qualitative analysis.

1) What are the similarities and differences in the graduation resources used by the defense lawyers in US and China courts?

2) How the defense lawyers utilize graduation resources to achieve their objectives in the defense process?

3) What are the possible reasons for the similarities and differences in the graduation resources used by the defense lawyers in US and China courts?

\section{Results and Discussions}

The statistical results show that the defense lawyers in the Wang Chengzhong case and the Stump case use graduation resources to varying degrees. As can be seen from Table 1, the number of graduation resources used by the defense lawyer in the Stump case is 77 and the number of graduation resources used by the defense lawyer in the Wang Chengzhong case is 105 , which shows that the attitudes and positions of the defense lawyers on both sides are very firm. But their frequency in the stump case is slightly lower than that in the Wang Chengzhong case. In both cases, the frequency of force resources is higher than that of focus resources. In the Case of Wang Chengzhong, the number of force resources is 99 and the number of focus resources is 6 . In the Stump case, the number of force resources is 57 and the number of focus resources is 20. It is apparent that the frequency difference between force resources and focus resources in the Wang Chengzhong case is larger than that in the Stump case. It can be seen that the defense lawyer in the Wang Chengzhong case uses scalable attitude resources more frequently.

Table 1 Percentage of graduation resources used by the defense lawyers in the Wang Chengzhong case and the Stump case

\begin{tabular}{|c|c|c|c|c|}
\hline & \multicolumn{2}{|r|}{ Stump } & \multicolumn{2}{|r|}{ Wang } \\
\hline Feature & $\mathrm{N}$ & Percent & $\mathrm{N}$ & Percent \\
\hline GRADUATION-TYPE & \multicolumn{2}{|r|}{$\mathrm{N}=77$} & \multicolumn{2}{|c|}{$\mathrm{N}=105$} \\
\hline force & 57 & $74.03 \%$ & 99 & $94.29 \%$ \\
\hline focus & 20 & $25.97 \%$ & 6 & $5.71 \%$ \\
\hline
\end{tabular}

\subsection{Force}

Force covers assessments as to degree of intensity and as to amount. The speaker can grade by intensity and quantity to achieve the up-scaling and down-scaling of speech (Martin \& White, 2005). As can be seen from Table 2 , there is little difference in the proportion of intensification and quantification resources in both cases. Upscaling resources are more frequently used in both parties. In courtroom debates, the purpose of the lawyer is to try to persuade the other side and the audience to accept or agree with a certain point, so both sides need to utilize upscaling resources to strengthen their own points and to enhance the persuasive power of the discourse. In the Stump case, up-scaling resources used by the defense lawyer account for $77.36 \%$, and down-scaling resources account for $22.64 \%$, which is a big difference. In the Wang Chengzhong case, the difference is much more apparent, with up-scaling resources accounting for $95.96 \%$ and down-scaling resources accounting for $4.04 \%$. The defense lawyer in the Stump case are more inclined to use down-scaling resources to weaken the inappropriateness of his clients' behavior, while the defense lawyer in Wang Chengzhong case are more inclined to use up-scaling resources to 
reinforce his opinions

Table 2 Percentage of force resources used by the defense lawyers in the Wang Chengzhong case and the Stump case

\begin{tabular}{|c|c|c|c|c|}
\hline & \multicolumn{2}{|r|}{ Stump } & \multicolumn{2}{|r|}{ Wang } \\
\hline Feature & $\mathrm{N}$ & Percent & $\mathrm{N}$ & Percent \\
\hline FORCE-TYPE & \multicolumn{2}{|r|}{$N=57$} & \multicolumn{2}{|r|}{$N=99$} \\
\hline intensification & 45 & $78.95 \%$ & 86 & $86.87 \%$ \\
\hline quantification & 12 & $21.05 \%$ & 13 & $13.13 \%$ \\
\hline QUANTIFICATION-TYPE & \multicolumn{2}{|r|}{$\mathrm{N}=12$} & \multicolumn{2}{|r|}{$\mathrm{N}=13$} \\
\hline number & 12 & $100.00 \%$ & 13 & $100 \%$ \\
\hline mass & 0 & $0.00 \%$ & 0 & $0.00 \%$ \\
\hline extent & 0 & $0.00 \%$ & 0 & $0.00 \%$ \\
\hline SCALE & \multicolumn{2}{|r|}{$N=53$} & \multicolumn{2}{|r|}{$N=99$} \\
\hline upscale & 41 & $77.36 \%$ & 95 & $95.96 \%$ \\
\hline downscale & 12 & $22.64 \%$ & 4 & $4.04 \%$ \\
\hline
\end{tabular}

4.1.1 Intensification

As can be seen from Table 2, both the Stump case and the Wang Chengzhong case have a relatively high percentage of intensification resources, striking respectively $78.95 \%$ and $86.87 \%$. The speaker can assess degree of intensity over qualities, over amounts and repetitions.

The intensification of quality can be achieved by superlative forms, adjective modifier, etc., such as "obvious" and "both". For example:

(1) Judge Stump is a Judge of a considerable experience and I will indicate to this Court, a Judge of the highest \{Intensification; Quality; Upscale\} integrity. (Stump v Sparkman case)

（2）虽林地不同于耕地，但依多年办案经验，1150 亩林地，20 年使用期限，60 万元总价，算下来每 年26 元/亩，明显过低，显然[ Intensification; Quality; Upscale]不合理。(王成忠案)

[The forest land is different from cultivated land, but based on many years of experience in handling cases, 1150 acres of forest land, 20 years of lifespan, a total price of 600,000 yuan, 26 yuan per acre per year is significantly too low, and apparently \{Intensification; Quality; Upscale\} unreasonable. (Wang Chengzhong case).]

The superlative form is also a kind of graduation resources. In example (1) "highest" is a high value graduation. The defense lawyer uses the graduation resource "highest" to reinforce Judge Stump's integrity, with the purpose to establish the image of Stump's integrity in the impression of judges and juries. In example (2), the graduation resources "obviously", "too" and "apparently" are used by the defense lawyer to modify the irrationality of 600,000 yuan, which indirectly implies that Judge Wang Chengzhong's decision to adopt the total price of 6 million yuan is reasonable. The use of graduation resources helps strengthen the intensity of discourse and effectively persuades the audience to naturally accept the speaker's points of view and to bring the audience closer together, thus creating an emotional resonance with the audience.

In addition to the intensification of qualities, intensification can also operate over processes, for example:

(3) Judge Stump surely \{Intensification; Process; Upscale\} had jurisdiction to consider the petition and to act there on. (Stump v Sparkman case)

(4) He did not order anything, he simply \{Intensification; Process; Downscale\} approved this. (Stump v Sparkman case)

(5) 起诉书也没有说清楚哪一项证据是应当采信而没有采信的，照这个逻辑这个罪名可以套在任何一个法 官的头上，王成忠必须[Intensification; Process; Downscale]采信客观证据优先。(王成忠案)

[The indictment doesn't make clear which evidence should be admissible but isn't accepted. In this logic, any judge can be accused. And Wang Chengzhong must \{Intensification; Process; Downscale\} have priority to adopt objective evidence. (Wang Chengzhong case).]

In example (3), the graduation resource "surely" implies that the speaker is extremely firm, and it helps reinforce the view that Judge Stump has jurisdiction to approve the mother's petition, and highlight the reasonableness of 
Judge Stump's actions, thus attracting the audience's attention to what the defense lawyer expects.

In example (4), the word "simply" is a kind of down-scaling resource, and when the client has already done something inappropriate, the defense lawyer tends to use this kind of low-value graduation resource to weaken the inappropriateness of his clients' actions and to ease the relationship with the victim. In example (5), since you have no evidence to prove which evidence should be adopted, it is nothing wrong for Wang Chengzhong to take preference to objective evidence. The graduation resource "must" helps strengthen the correctness of Wang Chengzhong's behavior. If the word "must" is replaced by the word "should", the attitude of the defense lawyer is not so firm.

You can also achieve intensification by repeating the same word, or by using semantically similar words. For example:

(6) 60 万元协议，虽然在林业站备案，但价格过低，违反 [Repetition; Upscale]社会共识，违反理性人常 识，违反经验法则，结合被上诉人主张的“避税”理由、双方承认曾以为要交税、鉴定价格 200 万左右、 郭长兴调解愿意接受 200 万等事实，该60 万合同显然是虚假的。(王成忠案)

[Although recorded in the forestry bureau, the price of 600,000 yuan is too low, which violates \{Repetition; Upscale, social consensus, violates the common sense of rational people, and violates the rule of experience. From the facts that the appellee argues "tax avoidance", both parties thinks they have to pay taxes, the identification price is about 2 million yuan, and Guo Changxing is willing to accept 2 million to reach agreement, it is apparent that a contract with a total of 600,000 yuan is clearly false. (Wang Chengzhong case).]

Repetition is a kind of way to reinforce your point of view. In example (6), the defense lawyer draws the attentions of the judge, jury, and the audience to the topic again by repeating it, thus holding the power of speech again. In example (6), the repetition of the word "violate" helps reinforce the idea that adopting the $\$ 600,000$ agreement will bring serious consequences and at the same time, inviting the reader to respond and to form an alliance with his position.

4.1.2 Quantification

In addition to enhancing the intensity of the discourse through intensification, the speaker also can choose quantification to align himself with the audience. Quantification can be achieved in three ways: number, mass, and extent, which includes distribution and proximity (Martin \& White, 2005). According to Table 2, the quantification resources used by the defense lawyer in the Stump case account for $21.05 \%$ and the quantification resources used by the defense lawyer in the Wang chengzhong case account for $13.13 \%$. In both cases, up-scaling resources are also used more frequently than down-scaling resources. And the number resources are used more frequently. That's because precise figure helps enhance the reliability of words and fuzzy figure helps weaken divergences and negative meanings. For example:

(7) He has been elected four \{Quantification; Number; Upscale\} times and is now serving his 20th [Quantification; Number; Upscale] year. (Stump v Sparkman case)

（8）多年来的 [Quantification; Number; Upscale] 审理经验表明，东辽县农村土地承包费每年在300-500 元 左右, 最高能达到 1000 元。依最低 300 元/年的标准计算, 涉案林地价值也达到 690 万元。(王成忠案)

[Many years \{Quantification; Number; Upscale\} of trial experience shows that the rural land contract fee in Dongliao County is about 300-500 yuan per year, up to a maximum of 1000 yuan. At a minimum of 300 yuan per year, the value of the woodland involved also reached 6.9 million yuan. (Wang Chengzhong case).]

In example (7), the quantitative resources are used by the defense lawyer to highlight the length of Judge Stump's tenure, which indirectly builds an image of Judge Stump's rich experience in the impression of the audience, and suggests that the Sparkman case was not handled arbitrarily and unjustifiably, thus weakening the inappropriateness of Judge Trump's approval. In example (8), the quantification resource "over the years" shows that Wang Chengzhong is a seasoned judge and adopting the 6 million yuan agreement is reasonable, and then use the actual quantitative data to support Wang Chengzhong's behavior. It can be seen that the use of quantitative resources helps make the discourse more objective and persuasive.

(9) I submit to the Court and made this decision as Courts of General Jurisdiction in every county, every day \{quantification; Number; Upscale\} throughout this country must make in matters of this particular type. (Stump v Sparkman case)

(10) 王成忠担任法官十几年兢故业业，尤其在审理该起民事案件中，未收当事人一分钱，未吃一顿饭 [Quantification; Number; Upscale]，无任何违规行为，更谈不上犯罪故意。(王成忠案)

[Wang Chengzhong has served as a judge for more than ten years with cautiousness and conscientiousness, especially in this civil case. Neither did he receive a penny \{Quantification; Number; Upscale\} from any party, nor did he have a meal [Quantification; Number; Upscale with any party. He doesn't conduct any unlawful act, let alone intentional crime. (Wang Chengzhong case).]

In example (9), the defense lawyer uses the quantitative resources "every day", "every county" to show that such cases are universal, weakening the particularity of the event, while strengthening discourse intensity. In example (10), the defense lawyer adopts the quantitative resources "more than ten years" to emphasize Wang Chengzhong's 
due diligence, and quantitative resources "a penny", "a meal" to show his incorruptibility, which denies the bribery crime identified in the first-instance judgment, thus correcting the audience's mind about Wang Chengzhong's bribery behavior.

\subsection{Focus}

Focus applies most typically to categories which are not scalable (Martin \& White, 2005). Martin and White argue that focus resources are the clearly bounded, either or categories which operate in experiential taxonomies where category membership is more or less precisely determined by some combination of sufficient and necessary conditions (Martin \& White, 2005). Martin and Hood further classify the focus resources into valeur and fulfilment to see how gradability operate over those scalable categories through graduation resources. Valeur deals with how the categorical boundaries of entities are graded in terms of authenticity and specificity. Fulfilment are concerned with how the boundaries of a process might also be graded in terms of completion and actualisation (Martin and Hood, 2007; Hood, 2011). As can be seen from Table 2, the number of focus resources used by the defense lawyer in the Stump case is 20, and the number of focus resources used by the defense lawyer in the Wang Chengzhong case is 6 . In the focus resources, the frequency of sharpening resources accounts for $45.00 \%$ in the Stump case, and the frequency of softening resources accounts for $55.00 \%$, with a little difference. In the case of Wang Chengzhong, the frequency of sharpening resources accounts for $66.67 \%$, and the frequency of softening resources accounts for $33.33 \%$. The defense lawyer in the Stump case uses softening resources more frequently to weaken the irrationality of his client 's behavior and to ease the tension with the opposed party.

Table 3 The proportion of focus resources used by the defense lawyers in the Wang Chengzhong case and the Stump case

\begin{tabular}{|c|c|c|c|c|}
\hline & \multicolumn{2}{|c|}{ Stump } & \multicolumn{2}{|c|}{ Wang } \\
\hline Feature & $\mathrm{N}$ & Percent & $\mathrm{N}$ & Percent \\
\hline $\begin{array}{l}\text { FOCUS- } \\
\text { TYPE }\end{array}$ & \multicolumn{2}{|r|}{$N=20$} & \multicolumn{2}{|r|}{$N=6$} \\
\hline soften & 11 & $55.00 \%$ & 2 & $33.33 \%$ \\
\hline sharpen & 9 & $45.00 \%$ & 4 & $66.67 \%$ \\
\hline
\end{tabular}

\subsubsection{Sharpen}

Sharpening is a semantic upgrade of the category of attitude that are not scalable, which reflects the speaker's recognition of discourse. Sharpening resources can clearly identify whether this expression is positive or negative and at the same time reinforces their positions. For example:

(11) 王成忠担任法官十几年兢兢业业，尤其[Focus; Specificity; Sharpen]在 审理该起民事案件中，未收当 事人一分钱，未吃一顿饭，无任何违规行为，更谈不上犯罪故意。(王成忠案)

[Wang Chengzhong has served as a judge for more than ten years with cautiousness and conscientiousness, especially [Focus; Specificity; Sharpen] in this civil case. Neither did he receive a penny from any party, nor did he have a meal with any party. He doesn't conduct any unlawful act, let alone intentional crime. (Wang Chengzhong case).]

In this example, the defense lawyer uses the sharpening resources "especially", to draw the audience's attention to this topic, guiding the audience to agree with this sentence, that is, Wang Chengzhong in the civil case is also cautious and conscientious without any act of bending the law.

(12) In this particular [Focus; Specificity; Sharpen] case the mother was the natural parent and guardian of this lady and she asks whether or not the Court would approve. (Stump v Sparkman case)

In this example, against the backdrop that the mother, as the guardian, asked the court to approve the petition, the sharpening resource "particular" highlights the typicality and specificity of the case and makes the scope of the experience clearer. Similar focus resources highlight the speaker's attitudes and intentions, and it is hoped that the audience will acknowledge his or her statement and acts accordingly.

4.2.2 Soften

The use of softening resources will produce an effect that is opposed to the effect of sharpening resources. Adjusting from the positive discourse, the audience is difficult to take a positive response, while adjusting from the negative discourse, the speaker's speech will become implicit, and to some extent helps avoid the other side's antipathy. So the softening focus resources has a better adjustment effect for negative words or behavior. This is why the defense lawyer in the Stump case uses softening resources more frequently.

(13) 补充一点, 追加第三人是因为他有可能[Focus; Actualisation; Soften]要 承担责任, 我们认为追加第三 


\section{人没有错。(王成忠案)}

[Let me add that the third person is added because he is likely \{focus; Actualisation; Soften\} to take the responsibility. And There's nothing wrong to add a third person. (Wang Chengzhong case)]

In this case, the reason for adding a third person is the subjective inference of the defense lawyer and the softening resource "may" reduces the absoluteness of the proposition, thereby positioning them as positions that are not easily challenged and persuading the reader to stand on the same front as the author.

(14) With this in mind, also there were not jurisdictional statutes in existence but there are statutes in existence on the State of the Indiana at that time which in general terms [Focus; Specificity; Soften] permitted parents to consent to medical treatment on behalf of their minor children. (Stump v Sparkman case)

The softening resource "in general terms" here serves as a vague concept. It is an indecisive statement showing that it is common practice for parents to consent to surgery on behalf of their minor children, which indicates the mother's behavior is reasonable. At the same time, the defense lawyer uses such softening resources to win the support while minimizing possible conflicts.

\subsection{Possible reasons for the similarities and differences in the graduation resources used by the defense lawyers in the Stump case and Wang Chengzhong case}

4.3.1 Possible reasons for the similarities in the graduation resources used by the defense lawyers in the Stump case and Wang Chengzhong case

From Table 1, Table 2, and Table 3, it can be seen that there are some similarities in the graduation resources used by the defense lawyers in the Stump case and Wang Chengzhong case. First, in both cases, the frequency of force resources is higher than that of focus resources. Force resources adjust the intensity of scalable attitude, while focus resources adjust the intensity of unscalable attitude. (Wang, 2001), so it is easy for force resources to reflect the attitude position of the speaker. And this is why the defense lawyers in both cases use force resources more frequently. Second, in force resources, up-scaling resources is much more frequently used than down-scaling resources. This is because the main task of the defense lawyer is to persuade judges and the audience and to protect the rights of his client. Up-scaling resources can render the speaker's voice stronger and more persuasive, thus building alliances with the audience, while down-scaling resources indicate that the speaker is uncertain when expressing his or her views. This is the reasons why the defense lawyer in both sides uses up-scaling resources more frequently. Third, the defense lawyer on both sides uses quantitative resources more frequently. This is because precise figure helps enhance the reliability and objectivity of words. To sum up, the possible reasons for the similarities in the graduation resources used by the defense lawyers in the Stump case and Wang Chengzhong case may lie in the functions of all kinds of graduation resources and the duties of defense lawyers.

4.3.2 Possible reasons for the differences in the graduation resources used by the defense lawyers in the Stump case and Wang Chengzhong case

Despite some similarities, there are still differences in the graduation resources used by the defense lawyers in the Stump case and Wang Chengzhong case. First, as can be seen from Table 1, force resources are used more frequently than focus resources in both cases. However, the frequency of force resources accounts for $74.03 \%$ in the Stump case, and the frequency of force resources accounts for $94.29 \%$ in the Wang Chengzhong case. Obviously, there is a great difference between force resources and focus resources in the case of Wang Chengzhong. This is because of the differences in the thinking way between the East and the West. Easterners pay more attention to emotional attitudes (Liang, 2012), while Westerners pay more attention to logical thinking (Hu \& Cao, 2011). Second, as can be seen from Table 3, in the Case of Wang Chengzhong, the proportion of sharpening resources is significantly higher than that of softening resources, while in the Stump case, the proportion of softening resources is higher than that of sharpening resources. The possible reason behind this is the differences of the two cases. In the Stump case, although the judge only approved the mother's petition, it is somewhat unethical to deprive a girl's right to have children, so the defense lawyer is relatively at a disadvantage. This is why the defense lawyer will use softening resources more frequently to weaken the irrationality of his client's behavior, and to ease the tension with the other party. However, in the Case of Wang Chengzhong, the defense lawyer firmly believes that Judge Wang Chengzhong in the civil judgment is not wrong, and there is evidence to overturn Wang Chengzhong case in the first instance of some unreasonable judgments. This is why the defense lawyer will rarely use softening resources. Instead, he uses sharpening resources more frequently to enhance his firm position. To sum up, Possible reasons for the differences in the graduation resources used by the defense lawyers in the Stump case and Wang Chengzhong case may be the cultural differences between China and the United States and the differences of these two cases.

\section{Conclusion}

Based on one of the subsystems of the appraisal system - the graduation system, this paper uses UAM Corpus Tool to count the frequency of various graduation resources in Wang Chengzhong case and the Stump case, and compares the similarities and differences in the graduation resources used by the defense lawyers in both sides to 
reveal the possible reasons behind them. The results show that: (1) there are some similarities in the graduation resources used by the defense lawyers in the Stump case and Wang Chengzhong case. The defense lawyer in both cases uses force resources more frequently than focus resources. This is because it is easy for force resources to reflect the attitude position of the speaker. In both cases, up-scaling resources is much more frequently used than down-scaling resources, this is because up-scaling resources can render the speaker's voice stronger and more persuasive, thus helping persuade the judge. there are still differences in the graduation resources used by the defense lawyers in the Stump case and Wang Chengzhong case. In the case of Wang Chengzhong, there is a great difference between force resources and focus resources used by the defense lawyer. This is because of the differences in the thinking way between the East and the West. Easterners pay more attention to emotional attitudes, while Westerners pay more attention to logical thinking. In the Case of Wang Chengzhong, the proportion of sharpening resources is significantly higher than that of softening resources, while in the Stump case, the proportion of softening resources is higher than that of sharpening resources. This is may be because of the differences between the two cases.

The limitations of this paper lie in that the selected cases are not widely representative and the annotation of graduation resources is inevitably subjective, but it is hoped that this paper can provide some implications for defense lawyers to use graduation resources properly.

\section{References}

Hood, S (2010). Appraising research: evaluation in academic writing. London: Palgrave Macmillan.

Hood. S \& J. R. Martin (2007). Invoking attitude: the play of graduation in appraising discourse. In Wang. Z.H (Eds.), Discourse semantics. Shanghai: Shanghai Jiaotong University Press.

Li, \& Li. (2019). An analysis of graduation resources in concession addresses. International Journal of Language and Linguistics, 7(3), 102-109.

Martin, J. R., (2000). Beyond exchange: appraisal systems in English. In S. Hunston and G. Thompson (Eds.), Evaluation in Text: authorial stance and the construction of discourse. Oxford: Oxford University Press.

Martin, J. R. \& White, P. R. (2005). The language of evaluation: appraisal in English. New York: Palgrave Macmillan.

Munday, J. (2015). Engagement and graduation resources as markers of translator/interpreter positioning. Target. International Journal of Translation Studies, 27(3), 406-421.

Peng, K., \& Nisbett, R. E. (1999). Culture, dialectics, and reasoning about contradiction. American Psychologist, 54(9), 741-754.

Chen, H., \& Sun, R, Y. (2020). The pragmatic rhetorical functions and intonation features of prosecutors' rhetorical questions from the perspective of appraisal theory. Contemporary Rhetoric, 39 (2), 82-95.

Dong, M. (2012). An analysis of the interpersonal meaning of debate discourses from the perspective of the graduation system. Foreign Language Studies, 29 (3), 14-20.

$\mathrm{Fu}, \mathrm{X} ., \& \mathrm{Fu}, \mathrm{T} .(2009)$. An analysis of English literary texts from the perspective of the graduation system a case study of Wuthering Heights, Journal of Hebei Normal University (Philosophy and Social Sciences Edition), 32 (3), 115-119.

Han, G., \& Mao, L. (2010). Engagement in court interaction. Journal of Heilongjiang Institute of Teacher development, 29 (10), 163-164.

Hu G \& Cao F. (2011). Hedging and boosting in abstracts of applied linguistics articles: A comparative study of English- and Chinese-medium journals. Journal of Pragmatics, 43(11): 2795-2809.

Jiang, G., \& X, D., (2019). A graduation analysis of “ One Belt, One Road" English news and teaching of English writing. Journal of Hangzhou Dian zi University (Social Sciences), 15 (2), 74-78.

Jiang, L. (2016). Interpersonal meanings of judges' engagement in courtroom discourse. Journal of Southwest University of Political Science \& Law, 18 (06), 123-129.

Liang, C. (2012). A brief introduction to thinking mode and translation strategies in English-Chinese translation. English Square (Academic Research), (09):8-11.

Pan, X. (2008). Engagement resources and the realization of persuasion in court debates. Rhetoric Learning, 27 (2), 50-55.

Si, B., \& Gao, S. (2019). A study on the distribution and translation of graduation resources in discourses for China's international communication. Shanghai Translation, 34 (5), 14-20.

Wang, H., \& G, Q. (2016). A contrastive study of graduation resources in English and Chinese linguistics book reviews. Journal of Ningbo University (Liberal Arts Edition), 29 (2), 32-37.

Wang, Z., \& Ma, Y. (2007). Evaluation theory: charm and confusion. Foreign Language Teaching, 28(6), 19-23.

Wang, Z. (2001). APPRAISAL systems and their operation: A New Development in the Systemic Functional Linguistics. Journal of Foreign Languages, 24 (06), 13-20.

Xie, L. (2017). The play of graduation in intersubjectivity of academic discourse. Tianjin Foreign Studies University, 24 (3), 39-45. 
Yuan, C., \& Hu, J. (2011). An adaptation analysis of engagement resources in lawyer representation. Language Teaching and Linguistic studies, 33(03), 87-94.

Yue, Y. (2011). Using engagement resources to construct interpersonal meaning in academic texts: A case study of Chinese students' MA theses. Contemporary Foreign Language Studies, 32(07), 30-35.

Zheng, J. (2013). Covert persuasion in lawyer's statement of defense-from the perspective of engagement system. Journal of Southwest Jiaoda University: Social Sciences Edition, 14 (4), 128-133. 